\title{
CIÊNCIA, UM MONSTRO: LIÇÕES TRENTINAS
}

FEYERABEND, Paul. Ciência, um monstro: lições trentinas. Tradução de Rogério Bettoni. Belo Horizonte: Autêntica, 2016. 232 p.

\section{Crysman Dutra Santos*}

Publicado em língua portuguesa no ano de 2016, Ciência, um monstro: lições trentinas contém uma série de palestras proferidas pelo físico e filósofo austríaco Paul Karl Feyerabend (1924-1994), que foi - juntamente com Karl Popper, Thomas Kuhn e Imre Lakatos - um dos filósofos da ciência mais respeitados do século XX. As conferências ocorreram entre os dias 4 e 8 de maio de 1992, na cidade de Trento, Itália. Além das quatro conferências que já estavam definidas, Feyerabend permitiu mais um encontro com o público, no qual foi feito um debate em que a plateia apresentava suas dúvidas e objeções quanto às palestras e às ideias anarquistas de Feyerabend. A edição brasileira foi traduzida por Rogério Bettoni e conta com um excelente artigo de abertura elaborado por Luiz Henrique de Lacerda Abrahão.

A despeito da multiplicidade de títulos que esse conjunto de conferências recebeu depois de se transformar em livro, a versão brasileira acabou intitulada de: Ciência, um monstro, em alusão a uma parte do seu percurso no qual Feyerabend remete à imagem de um monstro para se referir ao empreendimento da ciência, em que ele diz:

\begin{abstract}
Podemos tomar a ciência como um guia não só em questões práticas, como, ainda, em questões de significado, ideologia, ou conteúdo de vida. Mas também podemos aceitar a ciência como um guia em questões práticas - e nesse aspecto a ciência tem tido sucesso, mas só até certo ponto - e construir o resto da nossa visão de mundo partindo de fontes totalmente diferentes. Além disso, quem diz que é a ciência que determina a natureza da realidade presume que as ciências têm uma única voz. Acredita que existe um monstro, a CIÊNCIA, e que quando ela fala, repete e repete sem parar uma única mensagem coerente. Nada mais distante da verdade. Diferentes ciências têm ideologias muito distintas. [...] Vemos, portanto, que as ciências são repletas de conflitos. O monstro CIÊNCIA que fala como uma única voz é uma colagem feita por propagandistas, reducionistas e educadores (p. 85).
\end{abstract}

Por seu turno, esse título contém uma valiosa informação, a saber, o modo pelo qual Feyerabend visualiza a atividade científica, que de acordo com ele emana de uma fábula ou

\footnotetext{
* Graduação em Filosofia pela Faculdade Jesuíta de Filosofia e Teologia. E-mail: crysman1 @ hotmail.com.
} 
mito e que, consequentemente, repercute de modo decisivo na vida das pessoas "comuns". A princípio, a temática abordada nessas conferências seria acerca de tópicos relativos à teoria atômica. Esses tópicos, entretanto, foram posteriormente substituídos por duas questões fundamentais no horizonte do pensamento de Feyerabend. São elas: O que é conhecimento? O que é ciência?

Feyerabend inicia a primeira conferência (04/05/1992) relatando o entusiasmo dos cientistas adeptos à teoria do Big Bang, em decorrência da coleta de novas evidências em favor da cosmologia do Big Bang. Por outro lado, apesar de tamanha ampliação do conteúdo explicativo e das descobertas mais recentes das ciências naturais, ainda temos que conviver com uma ampla gama de problemas sociais.

No que diz respeito a esse ponto, Feyerabend menciona o abuso de poder coercitivo para com os negros por parte dos policiais de Los Angeles e os conflitos étnicos e religiosos pelo qual a antiga Iugoslávia ${ }^{1}$ passava na época em que ele estava exibindo esse ciclo de palestras. Além disso, ele conclui que as atuais explicações científicas conduzem a uma ausência de explicação teleológica, ou seja, aparentemente não há espaço para a finalidade ou propósito em um universo mecanicista, impregnado de ciência e razão. Ao que parece, a despeito do sucesso da ciência, restavam algumas lacunas, isto é, algumas perguntas permaneceram sem respostas. Segundo Feyerabend alguém poderia objetar que dar esperança e conferir sentido à vida não é tarefa da ciência, mas sim da religião. No entanto Feyerabend discorda veementemente dessa tese, uma vez que ele afirma que a religião não é um sistema singular e uniforme. Assim como na arte, na ciência e na filosofia, a ciência comporta uma pluralidade de opiniões entre grupos subdivididos em diversas doutrinas. Com efeito, um dos argumentos mais impactantes de Feyerabend ao longo de todo o seu percurso filosófico diz respeito à multiplicidade de ideias e teorias. De acordo com essa postura, harmonia e coesão não combinam com nenhuma das instâncias realizadas pelos humanos (arte, ciência, filosofia, religião, etc.). Para ele, é um equívoco falar, em sentido estrito, sobre "A Arte”, "A Ciência”, "A Filosofia”, "A Religião". O que de fato existem são várias correntes de pensamento dentro da arte, da ciência, da filosofia, da religião, e assim sucessivamente.

1 A desintegração do território iugoslavo culminou com a formação de vários Estados independentes. Entre eles se encontram: Sérvia, Bósnia-Herzegovina, Croácia, Montenegro, Eslovênia, Macedônia e mais recentemente, o Kosovo. 
Todavia, para Feyerabend essa multiplicidade desordenada se afigura justamente como uma grande vantagem. Portanto, uma vez que os indivíduos são diferentes, então suas realizações serão diferentes. Embora sejam áreas diferentes - a ciência, a religião, a filosofia, a arte, entre outras - há uma peculiaridade compartilhada que as une, isto é, todas elas lutam entre si com o intuito de ser hegemonicamente o "professor" exclusivo a respeito das leis naturais, do sentido da vida, do princípio e do fim. De tal maneira que elas pretendem oferecer respostas conclusivas às indagações humanas. Com efeito, Feyerabend ressalta que tal atitude não nos leva a lugar algum. Ele diz que embora haja essa luta ideológica, cada pessoa opta por um ou vários "professores". Tal conflito existe até mesmo entre membros do mesmo grupo ideológico. Uma tese defendida por Feyerabend no decorrer dessa conferência é a de que todas essas tradições são resultantes de visões de mundo. Além disso, há ainda a seguinte interrogação subjacente à conferência: É possível conciliar a VERDADE do universo aduzida pela CIÊNCIA com os efêmeros eventos do mundo sublunar? De acordo com Feyerabend, tal tentativa ocupou uma parte central das epopeias de Homero. Ele alega que os textos de Homero não eram lidos somente com mera curiosidade, mas que esses textos integravam de modo crucial a formação e a educação do homem grego, uma vez que refletiam a visão de mundo adotada pelos membros daquela cultura. Ademais, é pertinente salientar que as visões de mundo certamente introduzem uma ontologia própria e um conjunto de valores ortodoxos, ou seja, introduzem também uma axiologia própria. Feyerabend nos apresenta àquele que é considerado o primeiro filósofo do Ocidente, Tales de Mileto. Seu nome também repercute na geometria, através da demonstração do teorema do "triângulo raso" (cujos lados totalizam 180 graus); na astronomia, entre outros feitos extraordinários relatados, sobretudo por Platão e Aristóteles. Mas qual seria o papel de Tales para a filosofia? Qual é a característica que lhe permite ser classificado como o primeiro filósofo de que possuímos registro?

É de extrema importância destacar que o legado de Tales foi central para a tradição racionalista que se difundiu no lado ocidental do globo terrestre, pois Tales foi a primeira figura - da qual temos registro - que ousou a romper parcialmente com o mito. É bem verdade que não foi um rompimento total, é claro. Mas já representou uma mudança de paradigma, para nos remetermos a Thomas Kuhn. Essa mudança fez com que Tales começasse a procurar na natureza (physis) o princípio (arché) da ordem (kósmos) segundo o qual Tales presumia ser a água. Foi desse momento em diante que a explicação mítica cedeu lugar ao discurso racional (lógos). E consequentemente, a tradição iniciada por Tales, que 
busca uma unidade fundamental em meio a um emaranhado de aparência - deduz Feyerabend -, antecipou o percurso metodológico da ciência moderna. Para entender de que maneira aconteceu essa mudança de paradigma, é preciso retornar às fontes doxográficas disponíveis. Feyerabend admite que sabemos muito pouco a respeito dos pré-socráticos e que os documentos dos quais extraímos informações sobre o pensamento desses "professores" é extremamente obscuro e desconfiável. Nesse aspecto, Feyerabend (p. 54-55) faz uma constatação bastante interessante: "Portanto, desconfie quando ouvir alguém, como eu, dizer que 'Anaximando afirmou que...', afinal, tudo que sabemos de Anaximandro está em apenas uma frase - bastante confusa, alias!” Mas antes do aparecimento e consolidação do lógos era o mythós que ditava as regras do jogo. Ao lado do discurso mítico, havia os textos de Homero e Hesíodo que eram recitados pelos aedos e rapsodos. E igualmente havia o teatro grego, palco da tragédia e da comédia, local em que se destacavam as figuras de Ésquilo, Sófocles, Eurípedes e do excepcional comediante Aristófanes. A partir da interpretação dessas mensagens é que as pessoas conferiam sentido às suas existências e compreendiam onde se situavam no cosmo. Antes do advento do lógos e consequentemente da filosofia, este era o cenário grego, marcado pelo mito e religiosidade. Feyerabend encerra a primeira conferência comparando a tradição dos poetas antigos, antecessora da filosofia com o estado atual da arte e do seu papel para a humanidade.

Na segunda conferência (05/05/1992) Feyerabend retoma a citação do biólogo molecular Jacques Monod com a finalidade de inferir que à medida que o empreendimento científico avança, as pessoas vão se sentindo mais deprimidas em virtude da ausência de uma "providência" ou teleologia na natureza, o que culmina deixando as pessoas numa angustiante posição de solidão. Essa é uma das consequências mais calamitosas da visão de Feyerabend acerca do empreendimento da ciência. A proposta da segunda conferência fica imediatamente explícita: Feyerabend pretende mostrar as consequências da objetividade científica. E igualmente procura mostrar como tendências cientificistas e materialistas são injustificáveis de um ponto de vista epistemológico. Para tanto, promove uma crítica democrática à ciência. No cerne da questão, segundo Feyerabend, está a ganância provocada pelo capitalismo. A ciência depende de sua capacidade de produzir resultados, de modo que a relação entre benefício e prejuízo para as "pessoas comuns" é irrelevante, contanto que a ciência formule resultados. Para criticar a ciência não é preciso ser um especialista do ramo, alega 
Feyerabend, o que realmente precisamos - para efetuar este tipo de crítica - é de uma dose refinada de bom-senso.

À primeira vista parece que a ciência se constitui de fatos empíricos, cujas evidências se apoiam na observação e na experiência, sem urgir a teorias contrafactuais. Mas não é assim que funciona. Guiados apenas pela experiência, só nos é lícito perceber a diversidade, não a unidade. Para assegurar a presença dessa unidade é necessário postular forças e leis inobserváveis. Então "temos que concluir que a ciência não começou da experiência; ela começou questionando a experiência e sobreviveu considerando a experiência uma ilusão" (p. 70). É neste ponto que entra Parmênides. Para ele a mudança é uma ilusão dos sentidos e por trás dessa ilusão fenomênica, subjaz de modo fixo e imutável a fonte de todo discurso possível e de toda realidade concebível, o ser. "O ser é, o não-ser não é”, eis a grande proposição de Parmênides. Assim, o ser se identifica ao real e o não-ser à aparência. Os atomistas, como Leucipo e Demócrito, em contraposição à imobilidade de Parmênides afirmam que o ser é a matéria (ou átomo, que corresponde à parte indivisível da matéria), enquanto o não-ser é o vácuo, o espaço pelo qual a matéria atravessa. Assim, os atomistas não rejeitaram a mudança. Em seguida, Feyerabend (p. 73-74) elabora um resumo acerca da relação entre visão de mundo e ciência. Adiante ele se dirige em favor das questões da vida prática. Segundo ele, as prioridades foram invertidas no capitalismo. Por que cifras bilionárias são destinadas aos laboratórios de instituições de pesquisa para o mapeamento do genoma humano enquanto parte considerável está vivendo em condições precárias? A busca cartesiana por "ideias claras e distintas" não permitiu que a razão notasse quem realmente necessita de urgente auxílio: a própria humanidade. Se o racionalismo de Descartes se baseia no cânone de "ideias claras e distintas"; do lado do empirismo britânico, Francis Bacon acredita que a natureza deve ser submetida à verificação a fim de que possa desvelar seus segredos à astúcia da inquirição humana. Entretanto, o ideal de objetividade científica é amplamente contestado por Feyerabend. De acordo com ele, a ciência produziria melhores resultados se não menosprezasse a visão de mundo do "senso comum". Consultando a opinião e a experiência cotidiana das "pessoas comuns", os resultados das pesquisas científicas seriam úteis para aperfeiçoar a qualidade de vida das pessoas e evitaria uma ciência de "gabinete". Feyerabend (p. 78-79) escreve: 


\begin{abstract}
No entanto, o conhecimento existe e precisa ser usado. Repito que não estou sugerindo que a ciência deva ser descartada. Os cientistas descobriram que o conhecimento prático pode ser enganador de diversas maneiras (neste momento, penso principalmente nas descobertas de Pasteur). Minha tese é que erros acontecem também do outro lado e que o conhecimento prático pode corrigir os erros de uma abordagem científico-industrial. Desse modo, precisamos não de uma aplicação cada vez mais agressiva da ciência, que trata os habitantes locais como se fossem idiotas; precisamos de uma colaboração mais próxima entre os especialistas e as pessoas cujo ambiente os especialistas querem avaliar, modificar, melhorar. Tal abordagem não promete apenas resultados excelentes; ela já os atingiu em muitos países. Mas essa não é a sua única vantagem. O que importa é que a abordagem é muito mais humana do que um procedimento puramente objetivo que trata as pessoas comuns não como amigos ou colaboradores potenciais, mas sim como variáveis nem sempre bem-vindas, como possíveis elementos perturbadores.
\end{abstract}

Para terminar a segunda conferência, Feyerabend põe em cena Galileu. O astrônomo italiano é um dos personagens centrais da história da ciência na visão de Feyerabend. Ao propor o sistema heliocêntrico, Galileu estava indo contrariamente à ciência de seu tempo, estava sendo um irracionalista. Pois nos tempos de Galileu, somente alguém considerado desprovido de sanidade mental poderia questionar a cosmovisão de Aristóteles e Ptolomeu. Feyerabend analisa a condenação de Galileu. Na opinião de Feyerabend, havia bons indícios que pendiam tanto para o sistema geocêntrico, herdado de Aristóteles; quanto havia evidências em favor do sistema heliocêntrico de Copérnico-Galileu. Nesse sentido, Feyerabend acredita que a resposta sobre a razoabilidade da condenação de Galileu é uma questão de ponto de vista.

As últimas duas conferências consistem numa retomada dos assuntos discutidos nas anteriores. No que diz respeito à terceira conferência (06/05/1992), Paul Feyerabend retorna às origens do "milagre grego" a fim de explicitar como a tradição racionalista surgiu e se impôs à cultura ocidental. Nesse sentido, outra figura de vasta importância para a assunção da razão foi o poeta - denunciado por Feyerabend como "especialista" - Xenófanes. A concepção naturalista de Xenófanes gerou um agudo impacto na classe intelectual de Atenas, de modo que o mundo "real" perdeu o seu caráter humano, pois a postura das divindades dotadas de elementos antropomórficos fora ridicularizada nos escritos de Xenófanes, de modo que os deuses foram transformados em leis do pensamento. Além disso, a posição de Xenófanes converteu a natureza a uma posição cada vez menos animista. Foi exatamente neste ponto que houve uma drástica ruptura envolvendo de um lado a natureza (physis) e do outro a cultura (ethos). Essa separação desemboca na filosofia subsequente, entre o fisicalismo dos pré-socráticos, na antropologia de Sócrates e se acentua ainda mais na 
metafísica de Platão e Aristóteles. Nessa conferência, Feyerabend manifesta um desagrado em relação aos filósofos da ciência que se empenham em efetuar uma "reconstrução racional" da pesquisa científica, porque, de acordo com Feyerabend, esses filósofos cometem o erro de presumirem que as teorias científicas são essencialmente compostas de enunciados. No que se refere à distinção envolvendo teoria e prática, Feyerabend atribui a Platão a condição de filósofo dessa separação. Platão define a cópia do que podemos observar e sentir de opinião (doxa), mas tal aparência não é o suficiente para obter a verdade. A verdade reside além do que pode ser contemplado a partir dos dados dos sentidos; a prática não garante conhecimento. Conhecimento, para Platão, é conhecer em definição, conhecer essencialmente o que é e, portanto, reside no mundo das ideias. Assim, a trajetória da filosofia e, posteriormente, a da ciência foram alavancadas contrapondo fatos e ideias, teoria e prática. A busca arquetípica de Platão conduziu os rumos da filosofia de Descartes e da cosmologia de Galileu (a tese de um universo constituído de números de Pitágoras teve um impacto ainda mais profundo sobre Galileu). Eles continuaram buscando o fundamento abrangente da realidade. Após a revolução científica, muitos acreditaram que esse fundamento havia sido encontrado na mecânica. Todavia, sem sucesso, pois a mecânica não explica alguns processos naturais, tais como a meiose celular e doenças relacionadas à perda de memória. Na etapa final, Feyerabend nos oferece sua própria intepretação sobre a biografia de Pitágoras, realçando a tonalidade mística dos pitagóricos. A escola pitagórica tentou associar ciência, mente e religião. Os pitagóricos descobriram que a diagonal de um quadrado nem sempre pode ser expressa em números inteiros. Isso os deixou em apuros, de modo que eles se esforçaram para ocultar esse segredo. Porém, não foi possível esconder por muito tempo e desde então o teorema de Pitágoras veio à tona, implicando nas relações de $\mathrm{b}^{2}=2 \mathrm{a}^{2}$, sendo $b \mathrm{a}$ diagonal e $a$ os lados adjacentes.

Na quarta e derradeira conferência (07/05/1992), Feyerabend aborda a cisão entre a ciência e a política. A primeira lida com fatos das coisas que são; ao passo que a segunda trata do que deveria ser. Entre as idiossincrasias predominantes dos textos feyerabendianos é possível perceber o frequente uso de aspas para ironizar, o tom descontraído e a sutileza didática recorrente, contudo sem perder a riqueza e a profundidade de um exímio pensador. Assim, as conferências apresentadas em Ciência, um monstro podem ser lidas como uma conversa corriqueira de corredor, um diálogo cuja temática versa especialmente sobre ciência e razão e, suas implicações com os seres humanos. Sendo assim, é de suma importância 
retroceder no tempo com o objetivo de identificar e compreender de que maneira as tradições racionalistas e científicas despontaram até atingirem os atuais graus de respeitabilidade, visto que os ideais de razão e ciência são facetas que marcam indelevelmente o mundo contemporâneo. Avesso à sistematização, os textos que Feyerabend apresentou nas conferências seguem um curso dialético, desprovidos de qualquer intenção de se guiar cronologicamente. Feyerabend examina com mais detalhes o diálogo platônico Eutidemo. Nesse diálogo, Sócrates desafia Eutidemo a convencer Clínias de que é necessário amar a sabedoria e cultivar a virtude. Ao término da conversa, Eutidemo leva seu interlocutor a crer que tanto a resposta positiva quanto a negativa são aceitáveis. Os sofistas eram hábeis oradores e mostravam que através do discurso é possível afirmar e negar ao mesmo tempo sobre uma mesma coisa. Para concluir a quarta conferência, Feyerabend tece comentários sobre o que Michael Polanyi descreve como "conhecimento tácito". Feyerabend sustenta que o ofício do cientista não pode prescindir de um treinamento intenso e rigoroso, ele deve aprender a ver e agir de acordo com os ditames da metodologia da qual participa.

Após as conferências houve um debate, no qual Feyerabend oferecia suas respostas às dúvidas do público presente. Esse debate foi extremamente útil para o esclarecimento de certos aspectos do anarquismo metodológico de Feyerabend. O livro contém, ainda, uma compilação de testemunhos de alguns intelectuais acerca dos bastidores das conferências de Trento, bem como da personalidade excêntrica de Paul Karl Feyerabend. 